\title{
Data Management Knowledge, Practice and Associated Factors of Ethiopian Health Extension Workers in Gamo Gofa Zone, Southern Ethiopia: A Cross-Sectional study
}

Sewunet Sako Shagake ${ }^{1}$, Mezgebu Yitayal Mengistu² and Atinkut Alamirrew Zeleke ${ }^{3 *}$

${ }^{1}$ Department of Public Health Nursing, Arba Minch College of Health Science, Arba Minch, Ethiopia

${ }^{2}$ Department of Health Service Management, Institute of Public Health, College of Medicine and Health Science, University of Gondar, Gondar, Ethiopia

${ }^{3}$ Department of Health Informatics, Institute of Public Health, College of Medicine and Health Science, University of Gondar, Gondar, Ethiopia

\section{Abstract}

Background: Producing quality data for decision at all levels of the health system is a global imperative. According to the assessment of the Ethiopian National Health Information System done by the Federal Ministry of Health and World Health Organization, health information system resources, data management, dissemination and use were rated as "not adequate" among the six major components. The aim of this study was to determine the level of data management knowledge, practice and associated factors among Health Extension Workers.

Method: An institution based cross-sectional study was conducted from March 1-22, 2012, among Health Extension Workers deployed in Gamo Gofa Zone, Southern Ethiopia. A cluster sampling technique was used to select a sample of 457 participants. A structured self- administered questionnaire was used to collect the data. Data were entered using EPI info version 3.5.3 and analyzed using SPSS version 20 statistical packages. Descriptive statistics were used to describe the study population in relation to relevant variables. Bivariate and multivariate logistic regression was also carried out to see the effect of each independent variable on the dependent variable.

Results: The study revealed that $58.2 \%$ of study participants had good data management knowledge and nearly three-quarters $(74.3 \%)$ had a good data management practice. Workers who were supervised every 3 months [AOR= 4.204, 95\% Cl: (1.372-12.885)] and workers who have reporting formats in their office [AOR=2.631, 95\% Cl: $(1.331$ 5.203)] were more likely to have good data management knowledge. Moreover, workers who have of data registration books and reference materials in their office were more likely to have good data management practice with [AOR= $5.661,95 \% \mathrm{Cl}:(2.019-15.874)]$ and $[\mathrm{AOR}=1.870,95 \% \mathrm{Cl}:(1.178-2.968)]$ respectively.

Conclusions: Data management knowledge was found to be low whereas, data management practice was found to be high in the study area. Availability of reporting formats and frequency of supervision for data management knowledge, and availability of reporting formats and data registration book for data management practice of respondents were identified as significant determinants. Therefore, supplying adequate data management resources, modifying formats and improving frequency of supervision are necessary tasks to improve the data management knowledge and practice of Health Extension Workers in Ethiopia.

Keywords: Data management knowledge; Data management practice; Health extension worker

\section{Background}

Public health decision-making is seriously reliant on the timely availability of sound data. The role of health information systems is to generate, analyse and disseminate such data $[1,2]$. At the level of individuals and communities, information is needed for effective clinical management and for assessing the extent to which services are fulfilling community demands. At the higher level of the health system, health information capacitate health planners and managers to take decision regarding the effective functioning of health facilities and of the health system as a whole [3]

Since 2004, the government of Ethiopia has been strengthening and expanding its primary health care (PHC) system to improve access and equity in health care by launching the Health Extension Program (HEP) [4]. According to the Federal Ministry of Health (FMOH), Female Health Extension Workers (HEWs) responsible for providing packages of HEP, and are the first point of contact with the community with the health system delivering integrated preventive, promotive and curative health services, with a special focus on maternal and child health [5]. The program is specific to Ethiopia and it has sixteen basic health packages to be performed by HEWs. More than 35,000 HEWs were deployed nationwide to improve health status of families. All of
HEWs are expected to collect process and generate reports towards their day to day activities [6].

In Ethiopia data quality and use remain weak, particularly at district health offices and PHC facilities. Capacity building, standardized and integrated data collection and reporting, information use, and use of appropriate technology have been identified as critical factors to strengthening and improving health sector health management information system (HMIS) [7].

The availability of appropriately trained workers with analytical,

${ }^{*}$ Corresponding author: Atinkut Alamirrew Zeleke, Department of Health Informatics, Institute of Public Health, College of Medicine and Health Science University of Gondar, P.O.Box 196, Gondar, Ethiopia, Tel: +251581116221; E-mail atinkutresearch@gmail.com

Received December 18, 2013; Accepted February 12, 2014; Published February 18,2014

Citation: Shagake SS, Mengistu MY, Zeleke AA (2014) Data Management Knowledge, Practice and Associated Factors of Ethiopian Health Extension Workers in Gamo Gofa Zone, Southern Ethiopia: A Cross-Sectional study. J Health Med Informat 5: 150. doi:10.4172/2157-7420.1000150

Copyright: (c) 2014 Shagake SS, et al. This is an open-access article distributed under the terms of the Creative Commons Attribution License, which permits unrestricted use, distribution, and reproduction in any medium, provided the original author and source are credited. 
numerical and statistical skills is critical. A study done in North Gondar revealed that lack of skilled and trained manpower with deep knowledge of public health, competency on data collection, analysis and indicator calculation contributes for poor performance of existing health information system (HIS) in Ethiopia [8]. Assessment of utilization of HMIS done in north part of Ethiopia revealed that, out of $84.3 \%$ data collected daily, only $22.5 \%$ were utilized and $17.7 \%$ units of HIV/AIDS changed their data into information at district and facility level and used it for immediate decision making. From the total study units only $13.2 \%$ properly document their reports and registration books [9].

While data management knowledge and practice is critical at all level of the health workers in the use of information for decision making, [1] there was no previous studies which investigated the data management knowledge and practice of HEWs and associated factors in the study area. Therefore; this study will have greater input to program managers for designing programs, proper implementation and evaluation of their contribution. It could serve as base line for further study.

\section{Methods}

Institution based cross-sectional study was conducted from March 1-20 2012 among HEWs who have been working in Gamo Gofa Zone The study area is, one of the Zones of Southern Nation Nationality and People Regional (SNNPR) state of Ethiopia. The Zone covers 12,003.79 square kilometres ranging from low-arid to high-land $(600 \mathrm{~m}-4550$ $\mathrm{m})$ areas. Gamo Gofa Zone is divided into 15 wored as and 2 town administration which are grouped into 448 rural and 34 urban kebeles. The total population of this Zone is estimated to be $1,837,896$ most of them living in rural. The three zonal hospitals, 65 health centres, 466 health posts, 832 Rural Health Extension Workers (RHEWs) and 70 Urban Health Extension Workers (UHEWs), Clustering Sampling technique was employed to select the study participants. The sample size required (457) for this study was determined using single population proportion formula by considering the following assumptions: prevalence of data management knowledge 50\% (considering with no prior study), $95 \%$ level of confidence, $5 \%$ margin of error, design effect of 2 and $10 \%$ non-response rate. The numbers of clusters needed were selected by using lottery methods. All urban and rural HEWs who were working in the randomly selected wored as (clusters) were included. Eight (BSc in environmental health and health officers) coordinators were trained and assigned for data collection process.

Structured self-administered questionnaire was used to collect data. The questionnaire was prepared in English and it was translated to Amharic language (local language) to make it appropriate and easily understandable for the study participants. The Amharic version was again translated back to English to check the consistency of the meaning. As the HEP is a new program and has been practiced only in Ethiopia we could not find standardized questionnaire from national and international literatures. So we have prepared the questionnaire by looking Health Extension Workers job profile, in consultation with Health Extension Workers, program managers and pre-testing the questionnaire. Most of the questions were closed-ended with pre-coded responses, mainly grouped into socio-demographic characteristics, knowledge of data management and practice of data management, organizational factors and technical factors.

\section{Operational definition}

1. Good knowledge: HEWs who scored five points and above out of ten questions prepared for assessment of knowledge.
2. Poor knowledge: HEWs who scored below five points out of ten questions prepared for assessment of knowledge.

3. Good practice: HEWs who scored six points and above out of nine questions prepared for assessment of practice.

4. Poor practice: HEWs who scored below six points out of nine questions prepared for assessment of practice.

\section{Data management knowledge}

It focus on the specific knowledge of knowing how to collect, process, analyse data, knowing how and where to report the finding for the sixteen basic health packages collected by Health Extension Workers as their routine day to day work.

\section{Data management practice}

Focus on the ability to collect, process data, analyse data, able to present the finding using table, graphs for the sixteen basic health packages collected by Health Extension Workers as their routine day to day work.

Data were entered into Epi-Info Version 3.5.1 and exported to SPSS Version 20 for analysis. Frequencies, proportions and summary statistics were used to describe the study population in relationship to the relevant variables. Bivariate and multivariate logistic regression was computed out to see the effect of each independent variable on the dependent variable. Odds ratio and $95 \%$ CI were computed to assess the strength of the association and the statistical significance. A p-value of less than 0.05 was used for statistical significant associations

The study was approved by University of Gondar, College of Medicine and Health Science, Institute of Public Health Ethical Committee, and written informed consent was obtained from the study participants.

\section{Results}

Four hundred twenty one HEWs participated in the study with a response rate of $92.1 \%$. The mean age of participants was $24.4 \pm 3.33$ years. Of the total participants, 296 (70.3\%) were Protestants and 390 (92.6\%) were from the Gamo ethnic group. 258 (61.3\%) were married. Most of the participants (92.2\%) were rural HEWs. More than fifty percent $(56.3 \%)$ had work experience of 4-6 years (Table 1 ).

\section{Data management knowledge}

Of the 421 participants, 245 (58.2\%) respondents have good knowledge of data management, $402(95.5 \%)$ respondents reported that they knew data processing, and almost all (98.6\%) respondents know to whom they report the performed activities.

From the types of data collection methods, 375 (89.1\%) respondents know interview as data collection method followed by record review 161(38.2\%) and observation 158 (37.5\%).

\section{Data management practice}

Almost three fourth $(74.3 \%)$ of the respondents have good data management practice. Significant number of respondents, 394 (93.6\%) keep document of the last survey and 334 (79.3\%) agree that redundant data affect the quality of data. Fifty three (12.6\%) respondents make appropriate decision without timely information and $411(97.6 \%)$ respondents can make report for the collected data by themselves.

Almost all 409 (97.1\%) of the respondents use information at their hand for day-to-day activities, out of which 403 (74.3\%) HEWs have good data management practice. Incompleteness of the information 


\begin{tabular}{|c|c|c|}
\hline Socio-demographic Variables & Frequency & Percentage \\
\hline \multicolumn{3}{|l|}{ Age } \\
\hline 1. $<=20$ years & 50 & $11.9 \%$ \\
\hline 2. $21-30$ years & 352 & $83.6 \%$ \\
\hline 3. $31-40$ years & 19 & $4.5 \%$ \\
\hline \multicolumn{3}{|l|}{ Religion } \\
\hline 1. Protestant & 296 & $70.3 \%$ \\
\hline 2. Orthodox & 123 & $29.2 \%$ \\
\hline 3. Muslim & 2 & $0.5 \%$ \\
\hline \multicolumn{3}{|l|}{ Educational status } \\
\hline $1.10+1$ & 388 & $92.2 \%$ \\
\hline 2. diploma & 33 & $7.8 \%$ \\
\hline \multicolumn{3}{|l|}{ Marital status } \\
\hline 1. Single & 160 & $38.0 \%$ \\
\hline 2. Married & 258 & $61.3 \%$ \\
\hline 3. Divorced & 1 & $0.2 \%$ \\
\hline 4. Widowed & 2 & $0.5 \%$ \\
\hline \multicolumn{3}{|l|}{ Ethnicity } \\
\hline 1. Gamo & 390 & $92.6 \%$ \\
\hline 2. Zaise & 11 & $2.6 \%$ \\
\hline 3. Gofa & 9 & $2.1 \%$ \\
\hline 4. Gidicho & 2 & $1.6 \%$ \\
\hline 5. Others & 8 & $2.1 \%$ \\
\hline \multicolumn{3}{|l|}{ Place of residence } \\
\hline 1. Rural kebele & 381 & $89.6 \%$ \\
\hline 2. Urban kebele & 40 & $10.4 \%$ \\
\hline \multicolumn{3}{|l|}{ Respondent monthly income } \\
\hline 1. $908.00 \mathrm{ETH}$ birr & 388 & $92.2 \%$ \\
\hline 2. $1233.00 \mathrm{ETH}$ birr & 33 & $7.8 \%$ \\
\hline \multicolumn{3}{|l|}{ Years of service } \\
\hline 1. $1-3$ years & 130 & $30.9 \%$ \\
\hline 2. 4-6 years & 237 & $56.3 \%$ \\
\hline 3. $7-9$ years & 54 & $12.8 \%$ \\
\hline \multicolumn{3}{|l|}{ Possession of radio/television } \\
\hline 1. Yes & 223 & $53.0 \%$ \\
\hline 2. No & 198 & $47.0 \%$ \\
\hline
\end{tabular}

Table 1: Distribution of socio-demographic characteristics of Health Extension Workers in Gamo Gofa Zone, Southern Ethiopia, June, 2012 ( $n=421)$

(6.7\%), irrelevancy of the information (5.2\%) and inability to use it $(4.8 \%)$ were the main reasons reported for not using their own information for their daily activities.

\section{Organizational factors of health extension workers}

According to their response $134(31.8 \%)$ respondents did not have reference materials in their office. 404 (96.0\%) were supplied with registration books. More than half (56.5\%) of the respondents obtain pen and pencil from respective health office. Out of the total respondents, 394 (93.6\%) have been supervised by their supervisors. More than three-fourth (81.7\%) of the participants were supervised at least once in every month and the remaining $46(11.7 \%)$ and 26 (6.6\%) respondents were supervised once in every three and; six and above months respectively. Feedback from concerned body was given for 353 $(83.8 \%)$ respondents (Table 2 ).

\section{Technical factors of health extension workers}

There were no reporting formats for different activities in the 50 (11.9\%) respondents' office. From 371 (88.1\%) respondent who have the reporting formats in their office, $202(48.0 \%)$ respondents had face shortage reporting formats frequently. The existing reporting formats were too complex or difficult to understand for $105(24.9 \%)$ respondents. The main reasons for its complexity were use of uncommon words/ terms (60.0\%), abbreviations (25.7\%), and inconsistency of the formats (5.7\%), (Table 3).

Factors associated with data management knowledge and practice of HEWs

As shown in the bivariate models, data management knowledge was significantly associated with availability of registration book, availability of reporting formats, supervision, and frequency of supervision. However, in the multivariate logistic regression analysis, data management knowledge was associated significantly only with availability of reporting formats and frequency of supervision.

Accordingly, Health Extension Workers who had reporting format in their office were 2.6 times [AOR $=2.631,95 \% \mathrm{CI}$ : $(1.331-5.203)]$ more likely to have good knowledge than with no reporting format in their office. Those Health Extension Workers who were supervised every three months were 4 times [(AOR $=4.204,95 \% \mathrm{CI}$ : $(1.372-12.885)]$ more likely to have good knowledge when compared to those who were not supervised (Table 4).

\begin{tabular}{|c|c|c|}
\hline Variables & Frequency & Percentage \\
\hline \multicolumn{3}{|l|}{ Reference materials } \\
\hline 1. Available & 287 & $68.2 \%$ \\
\hline 2. Not available & 134 & $31.8 \%$ \\
\hline \multicolumn{3}{|l|}{ Registration book } \\
\hline 1. Available & 404 & $96.0 \%$ \\
\hline 2. Not available & 17 & $4.0 \%$ \\
\hline \multicolumn{3}{|l|}{ Supervised } \\
\hline 1. Yes & 394 & $93.6 \%$ \\
\hline 2. No & 27 & $6.4 \%$ \\
\hline \multicolumn{3}{|c|}{ Frequency of supervision } \\
\hline 1. Every month & 322 & $81.7 \%$ \\
\hline 2. Every 3 month & 46 & $11.7 \%$ \\
\hline 3. Every 6 month & 19 & $4.8 \%$ \\
\hline 4. Every year & 7 & $1.8 \%$ \\
\hline \multicolumn{3}{|c|}{ Have you ever received feedback } \\
\hline 1. Yes & 353 & $83.8 \%$ \\
\hline 2. No & 68 & $16.2 \%$ \\
\hline \multicolumn{3}{|l|}{ Relevance of feedback } \\
\hline 1. Yes & 406 & $96.4 \%$ \\
\hline 2. No & 15 & $3.6 \%$ \\
\hline \multicolumn{3}{|c|}{ Trained on data management } \\
\hline 1. Yes & 175 & $41.6 \%$ \\
\hline 2. No & 246 & $58.4 \%$ \\
\hline
\end{tabular}

Table 2: Organizational factors of HEWs in GamoGofa Zone Southern Ethiopia June, 2012

\begin{tabular}{|c|l|l|}
\hline \multicolumn{2}{|l|}{ Variables } & \multicolumn{2}{l|}{} \\
\hline Reporting formats & 371 & $88.1 \%$ \\
\hline 1. Available & 50 & $11.9 \%$ \\
\hline 2. Not available & \multicolumn{2}{l|}{} \\
\hline Shortage of reporting formats & 202 & $48.0 \%$ \\
\hline 1. Yes & 169 & $40.1 \%$ \\
\hline 2. No & & \\
\hline Supervised & 105 & $24.9 \%$ \\
\hline 1. Difficult to understand & 266 & $63.2 \%$ \\
\hline 2. Not difficult to understand & & \\
\hline Frequency of supervision & 63 & $60.0 \%$ \\
\hline 1. Uncommon words/terms & 27 & $25.7 \%$ \\
\hline 2. Abbreviations & 6 & $5.7 \%$ \\
\hline 3. Formats are inconsistent & 9 & $8.6 \%$ \\
\hline 4. Others & & \\
\hline Have you ever received feedback & 404 & $96.0 \%$ \\
\hline 1. Yes & 17 & $4.0 \%$ \\
\hline 2. No & & \\
\hline
\end{tabular}

Table 3: Technical Factors of HEWs in GamoGofa Zone, Southern Ethiopia, June 2012. 
Citation: Shagake SS, Mengistu MY, Zeleke AA (2014) Data Management Knowledge, Practice and Associated Factors of Ethiopian Health Extension Workers in Gamo Gofa Zone, Southern Ethiopia: A Cross-Sectional study. J Health Med Informat 5: 150. doi:10.4172/2157-7420.1000150

Page 4 of 5

\begin{tabular}{|c|c|c|c|c|c|}
\hline \multicolumn{2}{|l|}{ Variables } & \multicolumn{2}{|c|}{$\begin{array}{l}\text { Data management } \\
\text { Knowledge }\end{array}$} & \multirow{2}{*}{$\begin{array}{c}\begin{array}{c}\text { Crude OR } \\
\text { (95\% C.I.) }\end{array} \\
6.971(1.972-24.643)\end{array}$} & \multirow[t]{2}{*}{$\begin{array}{l}\text { Crude OR } \\
\text { (95\% C.I.) }\end{array}$} \\
\hline Registration book & Available & 242 & 162 & & \\
\hline & Not available & 3 & 14 & 1 & \\
\hline \multirow[t]{2}{*}{ Supervised } & Yes & 235 & 159 & $2.513(1.122-5.629)$ & \\
\hline & No & 10 & 17 & 1 & \\
\hline \multirow[t]{6}{*}{ Frequency of supervision } & Overall & & & ** & ** \\
\hline & Every month & 182 & 140 & $2.210(0.982-4.976)$ & $1.245(0.504-3.074)$ \\
\hline & Every 3 months & 36 & 10 & $6.120(2.143-17.476)$ & $4.204(1.372-12.885)$ \\
\hline & Every 6 months & 12 & 7 & $2.914(0.864-9.833)$ & $1.729(0.476-6.278)$ \\
\hline & Every year & 5 & 2 & $4.250(0.691-26.135)$ & $3.410(0.444-26.211)$ \\
\hline & None & 10 & 17 & 1 & 1 \\
\hline \multirow[t]{2}{*}{ Reporting formats } & Available & 227 & 144 & $2.802(1.517-5.179)$ & $2.631(1.331-5.203)^{*}$ \\
\hline & Not available & 18 & 32 & 1 & 1 \\
\hline
\end{tabular}

*Significant at $p<0.01,{ }^{*}$ Significant at $p<0.05$

Table 4: Multivariate logistic regression analysis for potential factors associated with data management knowledge of HEWs in GamoGofa Zone, southern Ethiopia, June, 2012.

\begin{tabular}{|c|c|c|c|c|c|}
\hline \multicolumn{2}{|l|}{ Variables } & \multicolumn{2}{|c|}{$\begin{array}{c}\text { Data management } \\
\text { Knowledge }\end{array}$} & \multirow{2}{*}{$\begin{array}{c}\begin{array}{c}\text { Crude OR } \\
\text { (95\% C.I.) }\end{array} \\
5.802(2.91-16.10)^{*}\end{array}$} & \multirow{2}{*}{$\begin{array}{c}\begin{array}{c}\text { Crude OR } \\
(\mathbf{9 5 \%} \text { C.I.) }\end{array} \\
5.661(2.019-15.874)\end{array}$} \\
\hline Registration book & Available & 307 & 97 & & \\
\hline & Not available & 6 & 11 & 1 & 1 \\
\hline \multirow[t]{2}{*}{ Feedback } & Received & 270 & 83 & $1.891(1.090-3.201)$ & - \\
\hline & Not received & 43 & 25 & 1 & \\
\hline \multirow[t]{2}{*}{ Reporting formats } & Available & 283 & 88 & $2.144(1.160-3.963)$ & - \\
\hline & Not available & 30 & 20 & 1 & \\
\hline \multirow[t]{2}{*}{ Reference material } & Available & 177 & 43 & $1.897(1.205-2.987)^{*}$ & $1.870(1.178-2.968)^{\star *}$ \\
\hline & Not available & 136 & 65 & 1 & 1 \\
\hline
\end{tabular}

*Significant at $p<0.05,{ }^{* *}$ Significant at $p<0.01$

Table 5: Multivariate logistic regression analysis for potential factors associated with data management practice of Health Extension Workers in GamoGofa Zone, June, 2012.

In the same way bivariate logistic regression analysis for data management practice was fitted and availability of registration book, reporting formats, feedback and availability of reference material were significantly associated. However, in the multivariate logistic regression analysis, data management practice was significantly associated with availability of data registration book and reference materials with [AOR=5.66, 95\% CI: (2.019-15.874)] and [AOR=1.897, 95\% CI: $(1.178$ 2.968)] respectively (Table 5).

\section{Discussion}

This study attempted to assess data management knowledge and practice of both urban and rural HEWs and its associated factors in Gamo Gofa Zone, southern Ethiopia. The overall data management knowledge of $58.2 \%$ HEWs was good according to operational definition set for measurement of data management knowledge. In this study data management knowledge was assessed by measuring the competence of HEWs for collecting, processing and reporting data.

This research showed that significant number (95.7\%) of the respondents used data at their hand for their daily activities, and $368(87.4 \%)$ of the respondents made decisions with having timely information. $92.2 \%$ respondents keep the documents of the last survey in their office to utilize the information in the future. In general, $74.3 \%$ of HEWs were categorized as having good data management practice based on the operational definition set to measure data management practice. $394(93.6 \%)$ respondents were supervised, of which 322 $(81.7 \%)$ were supervised at least once in every month which is better compared with the previously reported findings from north Gondar Zone $(34.7 \%)$ [9]. Another survey indicated that two-third of the health posts were supervised during the three months preceding the survey [10]. Feedback was given on the data reported to higher levels for $353(83.8 \%)$ respondents which is higher than the findings of study in north Gondar Zone, Ethiopia (12.2\%) [9]. The possible reasons for this difference might be the provision of motor cycles for supervisors in the current study.

The existing reporting formats were complex or difficult to understand for $105(24.9 \%)$ respondents. This finding is in line with assessment of health management information system [11] conducted in Addis Ababa health Bureau (25\%). In this study, frequency of supervision and availability of reporting formats were found to be the crucial factor in predicting data management knowledge status of HEWs. Thus, HEWs who had reporting formats in their office were 2.6 times more likely to report good data management knowledge than those who had no reporting formats in their office $[\mathrm{AOR}=2.631,95 \% \mathrm{CI}$ : (1.331-5.203)]. This may be because those who had reporting format in their office are expected to report their findings after performing other data management tasks such as collection, processing and analysis of their data.

The finding revealed that those Health Extension Workers who were supervised every three months were 4 times [(AOR=4.204, 95\% CI: (1.372-12.885)] more likely to have good knowledge than compared to those who were not supervised. Other supervision frequencies such as every month, every six months and every one year were not significantly associated. That means those HEWs who were supervised once in every month, 6 months and every year have no significant difference in their data management knowledge compared with no supervision at all. The possible reason might be the supervision type in every three month was more in-depth with knowledge acquiring 
component feedback mechanism although the quality of monthly supervision might be questionable.

This study showed the importance of the availability of data registration books and reference materials for good data management tradition. Health Extension Workers who had registration book were about six times $[\mathrm{AOR}=5.66,95 \% \mathrm{CI}$ : (2.019-15.874)] more likely to perform good data practice. Also, those HEWs who reported they had reference material on how to manage data were almost two times [AOR=1.897, 95\% CI: (1.178-2.968)] more likely to have good data management tradition compared with those who had not reference materials. This might be due to continuous supply of data management recourses to the health extension program which may result in increased utilization of the resources.

The challenges for this study were limited previous publications or validated data collection tools, and lack of defined competencies in data management knowledge and practice for HEWs. To overcome this extensive discussions have been made with HEWs, their supervisors and program managers. In line with this data management practice questions were assessed only by self-administered questionnaire with its associated limitations.

In conclusion, data management knowledge was found to be low whereas, data management practice was found to be high in the study area. The main determinants of data management knowledge and practice were mostly organizational and technical factors. The major factors identified include availability of reporting format, reference books and registration book and also frequency of supervision. Therefore, giving training for HEWs on data management to improve knowledge based work practices, modifying or briefing formats, improving frequency of supervision and provision of adequate and sustainable data management resource is mandatory. Further researches are needed using tools having greater observational components to assess the practice of data management.

\section{Conflict of Interest}

The authors declare that we have no conflict of interests.

\section{Authors' Contribution}

SS wrote the proposal, participated in data collection, analyzed the data and drafted the paper. MY and AA approved the proposal with some revisions, participated in data collection and analysis. All authors participated in the preparation of the manuscript and approved the final manuscript.

\section{Acknowledgement}

The authors would like to thank University of Gondar Department of Health Informatics for the financial support in the research process. We also would like to thank the Gamo Gofa Zone health department officials for their cooperation during data collection and other processes during the study.

\section{References}

1. Carla Abou Zahr TB (2005) Health information systems: the foundations of public health. Bulletin of the World Health Organization 83.

2. Aiga HKC, Takizawa I, Yamagata R (2008) The reality of health information systems: challenges for standardization. Biosci Trends 2: 5-9.

3. Aqil ALT, Hozumi D (2009) PRISM framework: a paradigm shift for designing strengthening and evaluating routine health information systems. Health Policy Plan 24: 217-228.

4. (2007) Federal Ministry of Health: Health Extension and Education Center: Health extension program in Ethiopia profile In. Addis Ababa, Ethiopia.

5. Banteyerga H (2011) Ethiopia's Health Extension Program: Improving Health through Community Involvement. MEDICC Rev 13: 46-49.

6. (2007) Health Extension and Education Center Federal Ministry of Health Health Extension Program In Ethiopia. In Addis Ababa, Ethiopia.

7. (2008) Federal Ministry of Health: HMIS Reform Team: Health Management Information System (HMIS) /Monitoring and Evaluation (MONITORING AND EVALUATION) Strategic Plan for Ethiopian Health Sector HMIS Reform Team. In.

8. Mengiste AS (2010) Analysing the Challenges of IS implementation in public health institutions of a developing country: the need for flexible strategies. Journal of Health Informatics in Developing Countries 4: 1-17.

9. Andargie G, Addisse M (2007) Assessment of utilization of HMIS at distrinformationcommuincation technology level with particular emphasis on the HIVIAIDS program in North Gondar Amhara Region Ethiopian Public Health Association (EPHA). Extract of MPH theses 3: 50-62.

10. Carter Center (2009) Evaluation of the Quality of Training of Health Officers and Quality and Utilization of Health Learning Materials: Report of an Independent Assessment. In Addis Ababa, Ethiopia.

11. Alganesh Ghebrehiwot (2005) Assessment of health management information system in Addis Ababa health bureau. 